
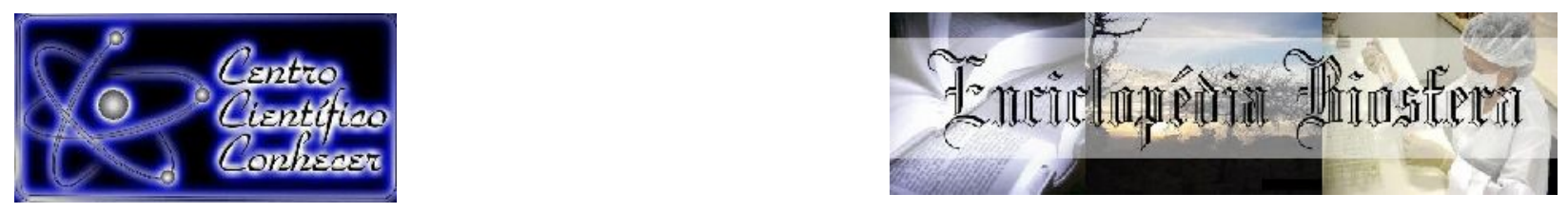

\title{
PRÉ-NATAL MASCULINO: A IMPORTÂNCIA DA PARTICIPAÇÃO DO PAI NAS CONSULTAS DE PRÉ-NATAL
}

\author{
Silma Costa Mendes ${ }^{1}$, Kezia Cristina Batista dos Santos ${ }^{2}$ \\ ${ }^{1}$ Enfermeira. Especialista em Enfermagem Obstétrica. São Luís-MA, Brasil. \\ ${ }^{2}$ Mestranda em Enfermagem pelo Programa de Pós-Graduação em Enfermagem da \\ Universidade Federal do Maranhão (UFMA). São Luís-MA, Brasil. \\ E-mail: kezia_cristinabs@hotmail.com
}

\section{Recebido em: 06/04/2019 - Aprovado em: 10/06/2019 - Publicado em: 30/06/2019 DOI: 10.18677/EnciBio_2019A163}

\begin{abstract}
RESUMO
Objetivou-se com este estudo analisar a importância da participação do pai nas consultas de pré-natal. Trata-se de uma revisão integrativa da literatura, de caráter descritivo e exploratório, realizada nas bases de dados da Literatura LatinoAmericana e do Caribe em Ciências da Saúde (LILACS); Banco de Dados de Enfermagem (BDENF) e Scientific Electronic Library Online (SCIELO). Incluíram-se estudos primários, publicados em português, inglês e espanhol, disponíveis na íntegra, entre os anos 2008 e 2018. A amostra foi constituída por 12 artigos. A análise dos dados permitiu a identificação de duas categorias temáticas que norteiam os estudos: "Fatores que dificultam ou influenciam a participação do pai nas consultas de pré-natal" e "Benefícios efetivos da participação do pai nas consultas de pré-natal". Observou-se o reconhecimento gradativo do pai em relação ao período gestacional, entretanto, este ainda encontra barreiras culturais e institucionais que o impedem de efetivar seu direito. A criação do pré-natal masculino incentiva a conscientização do homem em busca de sua adesão às novas ações propostas pelo sistema de saúde, mas para que essas medidas surtam efeito em grande escala, o reconhecimento acerca da importância da presença do pai no acompanhamento das consultas de pré-natal deve ser amplamente divulgado e estimulado.
\end{abstract}

PALAVRAS-CHAVE: Assistência pré-natal, pai, paternidade.

\section{MALE PRENATAL: THE IMPORTANCE OF FATHER PARTICIPATION IN PRENATAL CONSULTATIONS}

\begin{abstract}
The objective of this study was to analyze the importance of the father's participation in prenatal consultations. This is an integrative review of the literature, of a descriptive and exploratory nature, carried out in the databases of Latin American and Caribbean Literature in Health Sciences (LILACS); Nursing Database (BDENF) and Scientific Electronic Library Online (SCIELO). Primary studies, published in Portuguese, English and Spanish, available in full, between 2008 and 2018 were included. The sample consisted of 12 articles. The analysis of the data allowed the
\end{abstract}


identification of two thematic categories that guide the studies: "Factors that hinder or influence the participation of the father in prenatal consultations" and "Effective benefits of the father's participation in prenatal consultations". It was observed gradual recognition of the father in relation to the gestational period, however, he still finds cultural and institutional barriers that prevent him from effecting his right. The creation of male prenatal care encourages men to be aware of their commitment to the new actions proposed by the health system, but for these measures to take effect on a large scale, recognition of the importance of the presence of the father in the follow-up of consultations prenatal care should be widely publicized and encouraged.

KEYWORDS: fathers, paternity, prenatal care.

\section{INTRODUÇÃO}

Nos últimos anos muito tem se falado sobre a importância do envolvimento consciente e ativo do pai/parceiro no período pré-natal, não só como apoio emocional à gestante, mas também para a criação de vínculo afetivo com o bebê (BRASIL, 2016).

Historicamente, tanto o planejamento reprodutivo quanto as ações em saúde voltadas ao momento da gestação, parto e puerpério foram pensadas e direcionadas às mulheres e às gestantes, enfocando o binômio mãe-filho (BRASIL, 2016). Todavia, muitos homens de diferentes idades demonstram desejo de participar ou efetivamente participam em todos os momentos da gravidez, desde a decisão compartilhada de ter um filho, passando por todas as fases da gestação, até o desenvolvimento da criança (UNFPA, 2007).

A inserção do pai no pré-natal é um direito reprodutivo e sua participação torna-se cada vez mais frequente devendo sua presença ser estimulada durante as atividades de consulta pré-natal servindo para preparar o casal durante a gestação e para a hora do parto (FERREIRA et al., 2014; CAMPOS; SAMPAIO, 2015;). A implementação do pré-natal masculino faz parte de um movimento crescente no Brasil e no mundo que defende o envolvimento integral dos homens na gestação, no parto, no cuidado e na educação dos filhos (BRASIL, 2016).

O pré-natal masculino foi criado com a intenção de promover aumento da adesão dos usuários do sexo masculino nas unidades de saúde, utilizando estratégias educativas voltadas à participação paterna na gestação, parto e nascimento, e ao mesmo tempo, auxiliar na melhoria do acesso e acolhimento desta população (CABRAL et al., 2015).

No pré-natal, as informações disponibilizadas nas consultas proporcionam condições ao parceiro de entender as mudanças que ocorrem com a mulher nesse período e também orientá-los sobre o direito de acompanhar a gestante nas consultas pré-natais e no parto, um direito assegurado pela lei no 11.108/2005 (FERREIRA et al., 2014; CAMPOS; SAMPAIO, 2015). Além de representar momento oportuno para o cuidado à sua saúde, mediante fornecimento de orientações e realizações de teste e exames, servindo também como uma estratégia para aproximar os homens da medicina preventiva (BENAZZI et al., 2011).

Segundo Ribeiro et al., (2015) o envolvimento consciente e ativo do pai no ciclo gravídico-puerperal está relacionado a benefícios como diminuição do tempo de trabalho de parto, do uso de medicações e de cesáreas, aumento do índice de Apgar do bebê e amamentação duradoura. Ressalta-se, também, que esse envolvimento pode ser positivo não apenas para as crianças e mulheres, mas 
especialmente para os homens, por aproximá-los definitivamente da arena do afeto e do cuidado (BRASIL, 2016).

Contudo, ainda é possível encontrar obstáculos e resistências naturais nesse processo, uma vez que, envolve mudança de paradigmas e novos modos de trabalho, tanto por parte de gestores/as e trabalhadores/as de saúde como por uma parcela significativa da população masculina e feminina no que tange ao engajamento dos homens nesse tema (BRASIL, 2016).

Diante do exposto, é de grande relevância, que os profissionais de saúde minimizem a distância que já se faz histórica, dos pais/parceiros com o serviço de saúde, desenvolvendo práticas que sirvam para revisar a importância da família, paternidade e maternidade, motivando a participação do homem nas consultas de pré-natal juntamente com a sua companheira. Neste contexto, o presente estudo objetivou descrever a importância da participação do pai nas consultas de pré-natal.

\section{MATERIAL E MÉTODOS}

Trata-se de uma revisão integrativa da literatura, de caráter descritivo e exploratório, que seguiu as seguintes etapas: 1- identificação do tema e formulação da questão da pesquisa, 2- elaboração dos critérios de inclusão e exclusão de artigos relacionados, 3- definição das informações a serem extraídas dos estudos selecionados, 4- avaliação e análise dos artigos selecionados, 5- interpretação dos resultados obtidos, 6- apresentação da revisão e síntese do conhecimento (MENDES et al., 2008).

Inicialmente foi convencionado o tema: pré-natal masculino e a importância do pai nas consultas de pré-natal, e a formulação da seguinte questão norteadora da pesquisa: Qual a importância do pai nas consultas de pré-natal? A coleta de dados foi realizada no mês de maio de 2018 nas bases de dados Literatura LatinoAmericana e do Caribe em Ciências da Saúde (LILACS); Banco de Dados de Enfermagem (BDENF) e Scientific Electronic Library Online (SCIELO).

$O$ estabelecimento dos descritores da pesquisa foi realizado através da estratégia PICo, onde foram definidos a População/Paciente/Problema $(P)$ : pai/paternidade; Interesse (I): paternidade e Contexto (Co): pré-natal. A estratégia PICo representa uma abreviatura para os termos Paciente, Intervenção, Comparação e o "outcomes" (desfecho). Em caso de pesquisa não-clínica, como o presente estudo, os termos utilizados serão Paciente, Interesse e Contexto. Essa estratégia é fundamental na construção da questão norteadora e pergunta de pesquisa para a busca de evidências na literatura (SANTOS et al., 2007; TAKAHASHI et al., 2014).

Após esta etapa, foi realizada a identificação dos descritores relacionados aos termos da estratégia PICo. O termo População $(\mathrm{P})$ abrangeu os descritores DeSC: "pai" ou "paternidade"; Interesse (I): "paternidade"; e Contexto: "assistência prénatal". Foram realizadas combinações com os termos utilizando-se os operadores boleanos (delimitadores) "OR" e "AND", onde o primeiro foi usado para combinação dos descritores e palavras-chave comum a cada componente da estratégia PICo, e o segundo, para finalização da estratégia de busca, realizou-se a combinação dos três termos: (P) AND (I) AND (CO), resultando na seguinte estratégia de busca: "fathers" OR "paternity" AND "paternity" AND "prenatal care"

Incluíram-se artigos primários disponíveis em texto completo, acesso online aberto, em português, inglês ou espanhol, publicados entre 2008 e 2018, que evidenciassem a importância da participação do pai nas consultas de pré-natal. Em 
seguida, realizou-se a leitura dos títulos e resumos buscando os estudos que respondessem à questão norteadora.

Foram excluídos estudos secundários, cartas, comunicações breves, editoriais, relato de caso, teses, dissertações, publicações que não abordavam o assunto de interesse ou respondessem à questão norteadora e que estavam duplicados. A figura 1 apresenta o fluxograma de seleção dos estudos primários incluídos no estudo de acordo com as bases de dados pesquisadas.

Após a leitura dos textos completos dos artigos utilizou-se um instrumento de coleta de dados adaptado de Ursi (2005) (SOUZA et al., 2010), contendo os itens: título, autores, ano de publicação, país, tipo de estudo, objetivos, resultados, conclusão. A avaliação do conteúdo dos artigos ocorreu por meio de leitura exploratória e analítica dos textos e redação dos resultados. Para tratamento dos dados, utilizou-se a classificação por área temática.

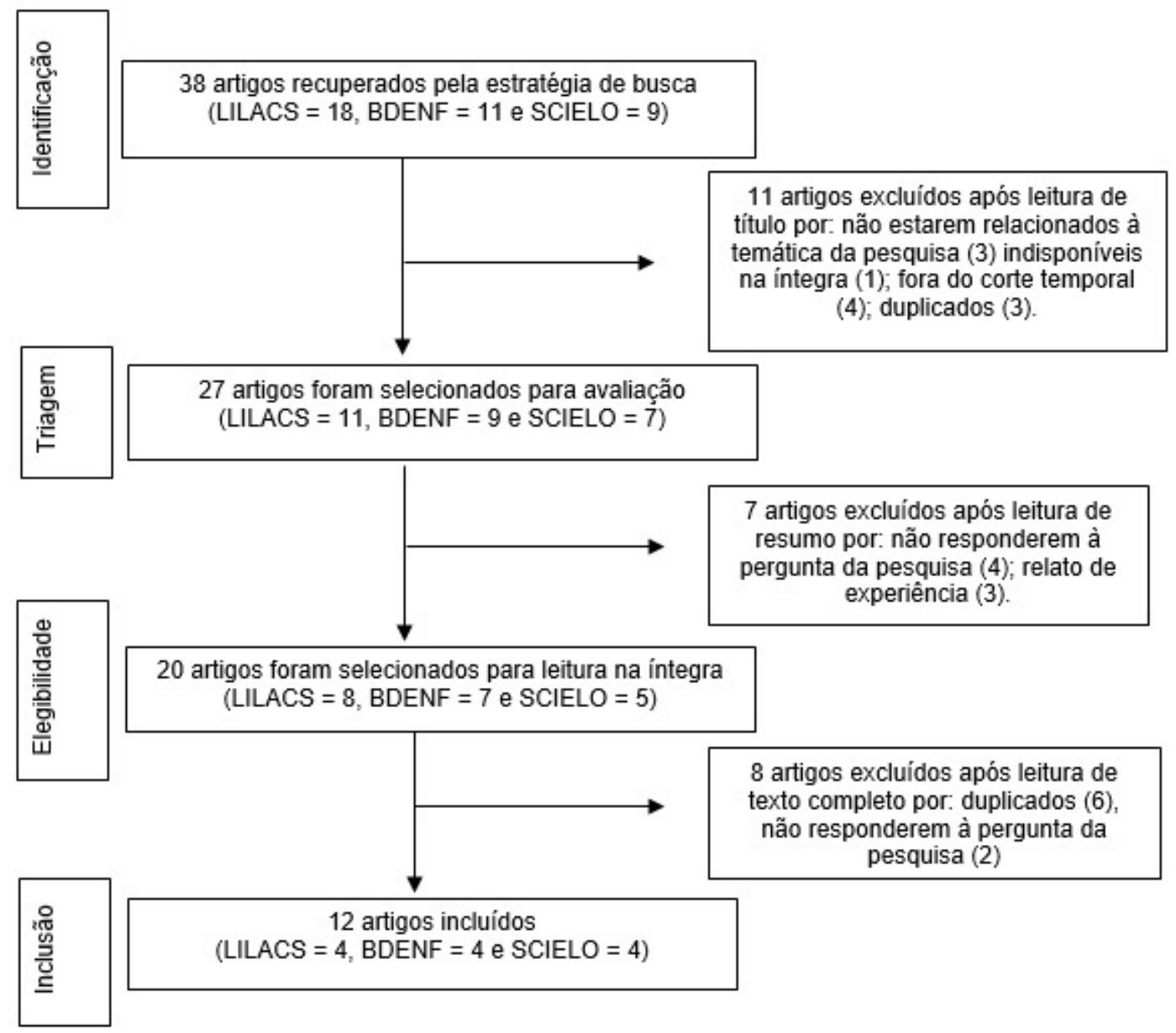

FIGURA 1: Fluxograma de seleção dos artigos incluídos na revisão integrativa segundo bases de dados. São Luís, MA, Brasil, (2018)

\section{RESULTADOS E DISCUSSÃO}

Doze estudos preencheram os critérios de elegibilidade e foram incluídos nesta revisão. O quadro 1, a seguir, apresenta a caracterização dos estudos levando-se em consideração o título, país e ano de publicação, objetivo, principais resultados e tipo de estudo. 
Entre os 12 artigos analisados identificou-se que todos foram realizados no Brasil e publicados no idioma português. Destacou-se o ano de 2017 com três artigos publicados. Quanto ao tipo de estudo, evidenciou-se 11 estudos observacionais descritivos e um analítico. Em relação ao delineamento metodológico, a maioria dos estudos apresentaram métodos de natureza qualitativa, sendo apenas três artigos caracterizados como quantitativos.

Para análise dos dados, os estudos foram agrupados em duas categorias de análise, devido similaridade temática, a saber: "Fatores que dificultam ou influenciam a participação do pai nas consultas de pré-natal" e "Benefícios efetivos da participação do pai nas consultas de pré-natal".

QUADRO 1: Caracterização dos artigos primários incluídos no estudo, São Luís, MA, Brasil, 2018

\begin{tabular}{|c|c|c|c|c|}
\hline Título & $\begin{array}{l}\text { País/ } \\
\text { Ano }\end{array}$ & Objetivo & Principais resultados & $\begin{array}{l}\text { Tipo de } \\
\text { estudos }\end{array}$ \\
\hline $\begin{array}{l}\text { Percepção de } \\
\text { gestantes acerca da } \\
\text { importância do } \\
\text { envolvimento paterno } \\
\text { nas consultas pré- } \\
\text { natal: um olhar de } \\
\text { gênero }\end{array}$ & $\begin{array}{l}\text { Brasil } \\
2008\end{array}$ & $\begin{array}{l}\text { Descrever a } \\
\text { participação do pai } \\
\text { nas consultas de pré- } \\
\text { natal, na percepção } \\
\text { das gestantes } \\
\text { entrevistadas; } \\
\text { caracterizar os } \\
\text { fatores que interferem } \\
\text { na participação ou } \\
\text { não do pai nas } \\
\text { consultas de pré- } \\
\text { natal; e analisar a } \\
\text { participação paterna } \\
\text { nessas consultas. }\end{array}$ & $\begin{array}{l}\text { Identificou-se que a presença } \\
\text { dos pais nas consultas do pré- } \\
\text { natal foi baixa e os motivos que } \\
\text { levaram à ausência dos } \\
\text { mesmos esteve relacionado às } \\
\text { próprias gestantes, como } \\
\text { vergonha; dos companheiros, } \\
\text { como coincidência com o } \\
\text { horário de trabalho; ou, ainda, } \\
\text { dos próprios serviços de } \\
\text { assistência pré-natal, que } \\
\text { podem restringir a participação } \\
\text { paterna. }\end{array}$ & $\begin{array}{l}\text { Descritivo, } \\
\text { observacional, } \\
\text { transversal, } \\
\text { qualitativo }\end{array}$ \\
\hline $\begin{array}{l}\text { A transição para a } \\
\text { paternidade: da } \\
\text { gestação ao segundo } \\
\text { mês de vida do bebê }\end{array}$ & $\begin{array}{l}\text { Brasil } \\
2009\end{array}$ & $\begin{array}{l}\text { Compreender a } \\
\text { transição para a } \\
\text { paternidade, } \\
\text { investigando as } \\
\text { expectativas e } \\
\text { sentimentos dos pais, } \\
\text { durante a gestação, e } \\
\text { a experiência da } \\
\text { paternidade após o } \\
\text { nascimento do bebê }\end{array}$ & $\begin{array}{l}\text { A análise de conteúdo } \\
\text { qualitativa das entrevistas } \\
\text { revelou que a gestação foi } \\
\text { vivida como emocionalmente } \\
\text { intensa, marcada por alegria, } \\
\text { ansiedade e conflitos. } \\
\text { Preocupações com a saúde da } \\
\text { esposa e do bebê e sentimentos } \\
\text { de exclusão mostraram-se } \\
\text { presentes. }\end{array}$ & $\begin{array}{l}\text { Descritivo, } \\
\text { observacional } \\
\text { longitudinal, } \\
\text { qualitativo }\end{array}$ \\
\hline $\begin{array}{l}\text { A participação do } \\
\text { homem/pai no } \\
\text { acompanhamento da } \\
\text { assistência pré-natal }\end{array}$ & $\begin{array}{l}\text { Brasil } \\
2009\end{array}$ & $\begin{array}{l}\text { Identificar os fatores } \\
\text { que influenciam a } \\
\text { participação do } \\
\text { homem/pai no } \\
\text { acompanhamento } \\
\text { pré-natal em uma } \\
\text { Unidade de Saúde da } \\
\text { Família de Recife - } \\
\text { PE }\end{array}$ & $\begin{array}{l}\text { Participaram do estudo } 13 \\
\text { pai/companheiros de gestantes. } \\
53,8 \% \text { referem o trabalho como } \\
\text { motivo para não participar do } \\
\text { pré-natal, } 61,5 \% \text { consideraram } \\
\text { como maior contribuição no } \\
\text { processo gestacional o apoio } \\
\text { emocional e financeiro e } 84,6 \% \\
\text { dos pais não participam dos } \\
\text { grupos de gestantes da unidade }\end{array}$ & $\begin{array}{c}\text { Descritivo, } \\
\text { observacional, } \\
\text { transversal, } \\
\text { quantitativo }\end{array}$ \\
\hline $\begin{array}{l}\text { Percepções e } \\
\text { experiências de } \\
\text { homens relativas ao } \\
\text { pré-natal e parto de } \\
\text { suas parceiras }\end{array}$ & $\begin{array}{l}\text { Brasil } \\
2010\end{array}$ & $\begin{array}{l}\text { Analisar a } \\
\text { participação de } \\
\text { homens no pré-natal } \\
\text { e parto de suas } \\
\text { parceiras. }\end{array}$ & $\begin{array}{l}\text { Os depoimentos revelaram que } \\
\text { a maioria das gestações não foi } \\
\text { planejada e que os homens não } \\
\text { acompanhavam suas parceiras } \\
\text { gestantes no pré-natal ou parto. }\end{array}$ & $\begin{array}{c}\text { Descritivo, } \\
\text { observacional, } \\
\text { transversal, } \\
\text { qualitativo }\end{array}$ \\
\hline $\begin{array}{l}\text { A ausência do } \\
\text { companheiro nas } \\
\text { consultas de pré- }\end{array}$ & $\begin{array}{l}\text { Brasil } \\
2012\end{array}$ & $\begin{array}{l}\text { Analisar a inserção e } \\
\text { visão do companheiro } \\
\text { acerca da assistência }\end{array}$ & $\begin{array}{l}\text { Dos doze entrevistados que } \\
\text { afirmaram acompanhar suas } \\
\text { esposas nas consultas de pré- }\end{array}$ & $\begin{array}{c}\text { Descritivo, } \\
\text { observacional, } \\
\text { transversal, }\end{array}$ \\
\hline
\end{tabular}




\begin{tabular}{|c|c|c|c|c|}
\hline $\begin{array}{l}\text { natal: desafios e } \\
\text { conquistas }\end{array}$ & & $\begin{array}{l}\text { pré-natal, identificar e } \\
\text { analisar os motivos } \\
\text { que levam a uma } \\
\text { parcela desses } \\
\text { companheiros a não } \\
\text { acompanharem suas } \\
\text { mulheres gestantes } \\
\text { nas consultas de pré- } \\
\text { natal. }\end{array}$ & $\begin{array}{l}\text { natal, } 42 \% \text {, afirmaram que não } \\
\text { entravam nas consultas. As } \\
\text { relações de gênero e a coerção } \\
\text { social induzidas por essas } \\
\text { relações influenciaram } \\
\text { fortemente a não participação } \\
\text { dos parceiros nas consultas de } \\
\text { pré-natal das gestantes. }\end{array}$ & qualitativo \\
\hline $\begin{array}{l}\text { O significado de ser } \\
\text { pai na ótica de casais } \\
\text { grávidos: limitações e } \\
\text { facilidades }\end{array}$ & $\begin{array}{l}\text { Brasil } \\
2012\end{array}$ & $\begin{array}{l}\text { Conhecer o } \\
\text { significado de ser pai } \\
\text { no processo de } \\
\text { nascimento e } \\
\text { identificar os fatores } \\
\text { limitantes e } \\
\text { favoráveis a esta } \\
\text { participação na } \\
\text { gestação, no parto e } \\
\text { pós-parto, na ótica } \\
\text { dos casais grávidos. }\end{array}$ & $\begin{array}{l}\text { A participação do pai deu-se em } \\
\text { função da sua disponibilidade e } \\
\text { presença em grupos educativos, } \\
\text { do estímulo da mulher e dos } \\
\text { profissionais. Os fatores } \\
\text { limitantes foram: machismo, } \\
\text { trabalho, desconhecimento dos } \\
\text { direitos, oposição das mulheres, } \\
\text { despreparo dos profissionais e } \\
\text { atividades educativas } \\
\text { insuficientes. }\end{array}$ & $\begin{array}{l}\text { Descritivo, } \\
\text { observacional, } \\
\text { transversal, } \\
\text { qualitativo }\end{array}$ \\
\hline $\begin{array}{l}\text { A importância da } \\
\text { participação paterna } \\
\text { durante o pré-natal: } \\
\text { percepção da } \\
\text { gestante e do pai no } \\
\text { município de } \\
\text { Cáceres-MT. }\end{array}$ & $\begin{array}{l}\text { Brasil } \\
2014\end{array}$ & $\begin{array}{l}\text { Descrever a } \\
\text { importância da } \\
\text { participação paterna } \\
\text { no acompanhamento } \\
\text { ao pré-natal na visão } \\
\text { do pai e da gestante. }\end{array}$ & $\begin{array}{l}\text { Participaram do estudo } 30 \\
\text { casais. } 76 \% \text { dos pais não } \\
\text { acompanharam as gestantes } \\
\text { durante a consulta, } 14 \% \text { às } \\
\text { vezes e } 10 \% \text { iam nas consultas. } \\
\text { Quanto aos pais que não } \\
\text { participam das consultas de } \\
\text { pré-natal ou que participam às } \\
\text { vezes, } 78 \% \text { das gestantes } \\
\text { relataram que o pai não } \\
\text { acompanha por motivos de } \\
\text { trabalho/serviço. }\end{array}$ & $\begin{array}{c}\text { Descritivo, } \\
\text { observacional, } \\
\text { transversal, } \\
\text { quantitativo }\end{array}$ \\
\hline $\begin{array}{l}\text { A visão das gestantes } \\
\text { acerca da } \\
\text { participação do } \\
\text { homem no processo } \\
\text { gestacional }\end{array}$ & $\begin{array}{l}\text { Brasil } \\
2017\end{array}$ & $\begin{array}{l}\text { Analisar a visão das } \\
\text { gestantes quanto à } \\
\text { participação do } \\
\text { homem durante o } \\
\text { processo gestacional } \\
\text { e as consultas de } \\
\text { pré-natal. }\end{array}$ & $\begin{array}{l}\text { A pesquisa apontou o apoio } \\
\text { ofertado em âmbito familiar } \\
\text { como essencial para a gestante } \\
\text { e a ausência do homem } \\
\text { durante a consulta foi entendida } \\
\text { e justificada pelo horário de } \\
\text { trabalho do companheiro, na } \\
\text { maioria das vezes. }\end{array}$ & $\begin{array}{l}\text { Descritivo, } \\
\text { observacional, } \\
\text { transversal, } \\
\text { qualitativo }\end{array}$ \\
\hline $\begin{array}{l}\text { Atenção à gestante } \\
\text { adolescente na rede } \\
\text { SUS - o acolhimento } \\
\text { do parceiro no pré- } \\
\text { natal }\end{array}$ & $\begin{array}{l}\text { Brasil } \\
2017\end{array}$ & $\begin{array}{l}\text { Verificar o } \\
\text { acolhimento e a } \\
\text { participação de } \\
\text { parceiros de } \\
\text { gestantes } \\
\text { adolescentes no pré- } \\
\text { natal da rede SUS. }\end{array}$ & $\begin{array}{l}\text { Houve o desejo do parceiro de } \\
\text { acompanhar as consultas do } \\
\text { pré-natal, mas este desconhece } \\
\text { seu direito de participar. Há } \\
\text { limites pessoais e institucionais } \\
\text { para efetivar a participação dos } \\
\text { parceiros. }\end{array}$ & $\begin{array}{l}\text { Descritivo, } \\
\text { observacional, } \\
\text { transversal, } \\
\text { qualitativo }\end{array}$ \\
\hline $\begin{array}{l}\text { A inclusão paterna } \\
\text { durante o pré-natal }\end{array}$ & $\begin{array}{l}\text { Brasil } \\
2017\end{array}$ & $\begin{array}{l}\text { Investigar a } \\
\text { participação paterna } \\
\text { durante o pré-natal } \\
\text { em um Centro de } \\
\text { Atenção à Saúde da } \\
\text { Mulher. }\end{array}$ & $\begin{array}{l}\text { A limitação da oferta de } \\
\text { horários de atendimento, que } \\
\text { coincidem com os de trabalho } \\
\text { dos homens dificulta a } \\
\text { participação paterna. Destacou- } \\
\text { se a importância de as } \\
\text { gestantes encorajarem o seu } \\
\text { parceiro a participar das } \\
\text { atividades do pré-natal. }\end{array}$ & $\begin{array}{l}\text { Descritivo, } \\
\text { observacional, } \\
\text { transversal, } \\
\text { qualitativo }\end{array}$ \\
\hline $\begin{array}{l}\text { A participação do } \\
\text { parceiro na rotina } \\
\text { pré-natal sob a } \\
\text { perspectiva da } \\
\text { mulher gestante }\end{array}$ & $\begin{array}{l}\text { Brasil } \\
2018\end{array}$ & $\begin{array}{l}\text { Analisar como a } \\
\text { gestante percebe a } \\
\text { participação do } \\
\text { parceiro na rotina } \\
\text { pré-natal }\end{array}$ & $\begin{array}{l}\text { Entre as } 11 \text { participantes do } \\
\text { estudo, apenas uma teve } \\
\text { acompanhamento integral do } \\
\text { parceiro, outras cinco relataram } \\
\text { a presença apenas na } \\
\text { realização da ultrassonografia } \\
\text { obstétrica. O trabalho foi } \\
\text { apontado como principal fator }\end{array}$ & $\begin{array}{c}\text { Descritivo, } \\
\text { observacional, } \\
\text { transversal, } \\
\text { qualitativo }\end{array}$ \\
\hline
\end{tabular}




\begin{tabular}{|c|c|c|c|c|}
\hline & & & $\begin{array}{l}\text { da ausência do companheiro, } \\
\text { questões de gênero também } \\
\text { influenciaram, pois, a gestação } \\
\text { é vista como momento } \\
\text { exclusivo da mulher. }\end{array}$ & \\
\hline $\begin{array}{l}\text { Influência da } \\
\text { participação do } \\
\text { companheiro no pré- } \\
\text { natal: satisfação de } \\
\text { primíparas quanto ao } \\
\text { apoio no parto }\end{array}$ & $\begin{array}{l}\text { Brasil } \\
2018\end{array}$ & $\begin{array}{l}\text { Correlacionar a } \\
\text { satisfação de } \\
\text { primíparas quanto ao } \\
\text { apoio e à utilidade do } \\
\text { companheiro durante } \\
\text { o processo de parto } \\
\text { com a sua presença } \\
\text { e capacitação no pré- } \\
\text { natal. }\end{array}$ & $\begin{array}{l}\text { A variável presença do } \\
\text { companheiro no pré-natal } \\
\text { esteve estatisticamente } \\
\text { associada à satisfação da } \\
\text { puérpera com o apoio } \\
\text { ( } \mathrm{p}=0,0004) \text { e com a utilidade do } \\
\text { apoio ( } \mathrm{p}=0,007) \text { durante o } \\
\text { trabalho de parto, enquanto a } \\
\text { variável capacitação do } \\
\text { companheiro no pré-natal } \\
\text { esteve estatisticamente } \\
\text { associada à satisfação com o } \\
\text { apoio ( } \mathrm{p}=<0,00001) \text { e à } \\
\text { utilidade do apoio ( } \mathrm{p}=<0,001 ; \\
\mathrm{p}=<0,00001 \text { e } \mathrm{p}=0,006) \\
\text { prestado pelo companheiro } \\
\text { durante todas as fases } \\
\text { avaliadas (trabalho de parto, } \\
\text { parto e pós-parto imediato). }\end{array}$ & $\begin{array}{c}\text { Analítico, } \\
\text { observacional, } \\
\text { transversal, } \\
\text { quantitativo }\end{array}$ \\
\hline
\end{tabular}

\section{Fatores que dificultam ou influenciam a participação do pai nas consultas de pré-natal}

Dos oito artigos incluídos nesta categoria todos evidenciaram a baixa participação ou ausência do pai no acompanhamento pré-natal de suas parceiras. Dentre os fatores citados que dificultaram ou influenciaram a não participação dos pais nas consultas de pré-natal estão: falta de tempo, coincidência com o horário de trabalho, desinteresse, relações de gênero, desconhecimento de sua participação como direito reprodutivo, a falta de informações, a postura de algumas mulheres que inconscientemente não deixam seus companheiros atuarem, a inexistência de serviços destinados aos homens, limites pessoais e institucionais (PESAMOSCA et al., 2008; OLIVEIRA et al., 2009; OLIVA et al., 2010; CABRITA et al., 2012; FERREIRA et al., 2014; COSTA, TAQUETTE, 2017; HENZ et al., 2017; CARDOSO et al., 2018).

A situação familiar da sociedade contemporânea sofreu profundas mudanças ao longo do tempo modificando as estruturas e os papéis dentro da dinâmica familiar; o homem já não é mais o único provedor e, em alguns casos, nem o principal (BENITÉZ; CÁRDENAS, 2010). Várias mudanças culturais, sociais, religiosas, políticas e econômicas colaboraram para que os papéis de pai e mãe na família fossem modificados. Todavia, é preciso destacar que, embora essas mudanças proporcionem aos homens a possibilidade de vivenciarem a paternidade de forma mais afetiva, ainda se observa a presença de barreiras e obstáculos que impedem a participação dos homens nesse tema (BENITÉZ; CÁRDENAS, 2010; ARPINI et al., 2016; BRASIL, 2016).

Tal fato, é oriundo de valores passados por uma cultura e uma sociedade patriarcal, ainda predominantemente machista, que defende a manutenção de papéis rígidos de gênero para mulheres e homens. Muitas vezes, incluindo a percepção de que a gestação e o cuidado de filhos/as dizem respeito 
exclusivamente às mulheres (BRASIL, 2016). Tal afirmativa reflete os achados encontrados no presente estudo.

Diversas pesquisas evidenciaram que as gestantes, em sua maioria, comparecem às consultas de pré-natal sozinhas ou acompanhadas por outras pessoas da família, que não o parceiro, dentre elas a mãe, a avó e amigas (PESAMOSCA et al., 2008; OLIVEIRA et al., 2009; OLIVA et al., 2010; CABRITA et al., 2012; FERREIRA et al., 2014; CARDOSO et al., 2018).

Um estudo realizado em Cáceres, Mato Grosso, identificou que dos 30 homens/pais entrevistados, $76 \%$ não acompanhavam as gestantes durante a consulta, $14 \%$ às vezes e apenas $10 \%$ acompanhavam as companheiras. Quanto aos pais que não participam das consultas de pré-natal ou que participam às vezes, 78\% não acompanhavam por motivos de trabalho/serviço (FERREIRA et al., 2014).

A situação trabalhista é uma das barreiras mais significativas que impedem a presença do pai nas consultas pré-natais. Atualmente, por mais que a mulher esteja inserida no mercado de trabalho, o homem ainda é reconhecido como o provedor da família, demonstrando papéis de gênero marcadamente divididos. A própria legislação remete a essa compreensão quando se compara, por exemplo, a diferença de tempo entre a licença maternidade e paternidade (COSTA et al., 2017). A maioria dos pais não consegue ir ao serviço de saúde acompanhar a parceira, pois não lhe é permitido se ausentar do trabalho (MARQUES, 2015). O horário de funcionamento das unidades de saúde que realizam o pré-natal também é citado como barreira para o acompanhamento das gestantes pelos parceiros, como evidenciado em outro estudo (HENZ et al., 2017; CARDOSO et al., 2018).

Outra pesquisa realizada na capital do Rio de Janeiro com 70 gestantes evidenciou o desconhecimento acerca da possibilidade e do direito da participação do parceiro no pré-natal e limitações institucionais para a inclusão do parceiro no serviço de saúde (COSTA et al., 2017).

No Brasil, uma grande parcela dos serviços do SUS não reconhece a participação do homem durante o pré-natal e não permite a presença de acompanhante durante a internação para o parto, ainda que se constitua em direito das mulheres garantido pela Lei no 11.108, de 07 de abril de 2005 (BRASIL, 2005; OLIVA et al., 2010). Outro agravante está no fato de que os espaços de saúde, particularmente os de atenção primária, são privilegiadamente femininos (CABRITA et al. 2012; COSTA et al., 2017). A falta de material ilustrativo e educativo, como fotos de homens com bebês, folders sobre a participação paterna no processo gestatório, dentre outros, pode induzir à interpretação de que se trata de um ambiente exclusivamente feminino (PESAMOSCA et al., 2008), contribuindo para o distanciamento do homem desses espaços.

Diante disto, o Ministério da Saúde, no intuito de incluir os homens nos debates e nas ações voltadas para o planejamento reprodutivo como uma estratégia essencial para qualificar a atenção à gestação, ao parto e ao nascimento, assim como, para a inclusão do tema paternidade e cuidado no serviços de saúde, desenvolveu o Pré-Natal do Parceiro por meio da Política Nacional de Atenção Integral à Saúde do Homem (PNAISH) (BRASIL, 2016).

O pré-natal masculino tem o objetivo de preparar o homem para o exercício da paternidade ativa, incluindo-o nas atividades educativas do pré-natal. O programa é, também, uma estratégia para aproximar os homens da medicina preventiva, uma vez que a população masculina sofre mais com o agravamento de doenças e procura atendimento médico já nos estágios mais avançados. Tem como ENCICLOPÉDIA BIOSFERA, Centro Científico Conhecer - Goiânia, v.16 n.29; p. 2127 
recomendação a inclusão do pai, na segunda consulta do pré-natal, em grupos de temas sobre masculinidade, gênero, saúde sexual e reprodutiva, paternidade e cuidado, hábitos saudáveis, prevenção de violência e de acidentes e direitos legais dos pais (BRASIL, 2016).

Assim, reforça-se que é necessário estimular um maior envolvimento do pai/parceiro durante todas as etapas da gravidez e pré-natal considerando a importância desta participação para o bem-estar da mãe, do bebê e dele próprio, para que o homem possa se sentir parte do integrante do processo gravídico e contribuir para a criação e/ou fortalecimento de vínculos afetivos saudáveis entre ele, sua parceira e filhos(as) (BRASIL, 2016; HENZ et al., 2017).

\section{Benefícios efetivos da participação do pai nas consultas de pré-natal}

Foram identificados quatro artigos que evidenciaram os benefícios efetivos da participação do pai no acompanhamento pré-natal das gestantes. Os benefícios são inúmeros, destacando-se: maior compreensão do pai sobre o processo de nascimento, apoio social e emocional do companheiro à gestante, aprendizagem dos cuidados com a mãe e bebê, preparo para o parto, fortalecimento dos potenciais e habilidades do casal e do pai para fazer escolhas e ajudar a companheira na gestação, parto e pós-parto, maior vínculo nas relações entre casal, assim como, impacto significativo na satisfação da puérpera com o apoio oferecido pelo parceiro e com a utilidade do apoio durante o trabalho de parto (KROB et al., 2009; ZAMPIERI, 2012; CALDEIRA et al., 2017; HOLANDA et al., 2018).

Tais benefícios adquiridos ainda na gestação refletem positivamente no momento do parto e puerpério proporcionando maior segurança, tranquilidade e autonomia ao casal, como observado nos estudos de Caldeira et al., (2017) e Holanda et al. (2018). Pesquisas realizadas no Brasil constataram que a realização de seis ou mais consultas de pré-natal, bem como o envolvimento do parceiro nessas consultas estiveram diretamente ligados à sua presença como acompanhante da mulher no trabalho de parto e parto (DINIZ et al., 2014; SOUZA; GUALDA, 2016). Isto reforça a importância da realização do pré-natal do parceiro e, consequentemente, a participação do pai no período gestacional.

Revisões sistemáticas recentes focadas no acompanhamento masculino de cuidados pré-natais para a saúde perinatal e o envolvimento masculino na saúde materna concluíram que o envolvimento do pai/parceiro é uma intervenção promissora (YARGAWA; LEONARDI-BEE, 2015; AGUIAR; JENNINGS, 2015). Esses estudos apoiam que as intervenções do envolvimento masculino podem ter efeito positivo na saúde materna e neonatal, utilização dos serviços de saúde e práticas de cuidado domiciliar como a amamentação. Uma revisão que incluiu a saúde mental materna como desfecho primário encontrou intervenções de envolvimento masculino associadas a depressão pós-parto reduzida (YARGAWA; LEONARDI-BEE, 2015).

O parceiro, quando estimulado efetivamente pelo profissional de saúde, participa ativamente da gestação de sua esposa/companheira, dando apoio emocional, contribuindo para as tomadas de decisão compartilhadas importantes acerca do tipo de parto, escolha da maternidade, assim como a efetivação de maior conhecimento relativo aos sinais de risco durante a gestação, parto e puerpério (KROB et al., 2009; HODNETT et al., 2013).

Cabe aos profissionais de saúde apresentar ao casal os seus direitos como pai, mãe, gestante, parturiente e puérpera, para que eles possam fazer valer as leis ENCICLOPÉDIA BIOSFERA, Centro Científico Conhecer - Goiânia, v.16 n.29; p. 2128 
e exercer a cidadania (CALDEIRA et al., 2017). Neste sentido, o enfermeiro é um dos elementos-chave no acolhimento do homem/pai na unidade de saúde e no estímulo de sua participação ativa no processo de nascer. Reitera-se que o acompanhante que participa das consultas de pré-natal oferece maior apoio à mulher em vista do nascimento de seu filho, fazendo com que a sua satisfação com esse evento seja ainda maior (GONZALEZ et al., 2012).

Pesquisa convergente assistencial realizada em Santa Catarina com cinco casais evidenciou que o processo educativo desenvolvido com os casais nas consultas pré-natais, visitas domiciliares e participação em grupos de casais grávidos configurou-se uma oportuna estratégia para inserção do pai desde o prénatal para o efetivo exercício da paternidade, proporcionando a abertura e valorização da figura paterna, entendimento dos novos papéis sociais do homem e mulher, desenvolvimento do processo educativo na atenção primária e estímulo dos profissionais, em especial, enfermeiros, para inclusão e participação do pai no prénatal (ZAMPIERI, 2012).

\section{CONCLUSÃO}

Esta revisão atualizou o conhecimento sobre o pré-natal masculino e a importância da participação paterna nas consultas de pré-natal. Os resultados deste estudo apontam para uma concentração de artigos voltados para as dificuldades/limitações, assim como os benefícios da participação do pai no período gestacional, entretanto, tem-se observado poucos avanços para solucionar tais problemas.

No contexto atual, observa-se o reconhecimento gradativo do pai em relação ao período gestacional, identificado na vontade do homem em querer participar desse processo e se preparar para o nascimento do filho, entretanto, este ainda encontra barreiras culturais e institucionais que o impedem de efetivar seu direito.

O Brasil tem investido numa política de atenção qualificada e humanizada. A criação do pré-natal masculino incentiva a conscientização do homem em busca de sua adesão às novas ações propostas pelo sistema de saúde, mas para que essas medidas surtam efeito em grande escala, o reconhecimento acerca da importância da presença do pai no acompanhamento das consultas de pré-natal deve ser amplamente divulgado e estimulado, principalmente pelos profissionais de saúde envolvidos diretamente na assistência, facilitando e viabilizando a participação paterna nesse processo.

\section{REFERÊNCIAS}

AGUIAR, C.; JENNINGS, L. Impact of male partner antenatal accompaniment on perinatal health outcomes in developing countries: a systematic literature review. Maternal and Child Health Journal. v. 19, n. 9, p. 2012-2019, 2015. Disponível em: <https://link.springer.com/article/10.1007\%2Fs10995-015-1713-2 >. Acesso em: 22 out. 2018. doi: https://doi.org/10.1007/s10995-015-1713-2

ARPINI, D. M.; CÚNICO, S. D.; ALVES, A. P. Paternidade: O Ponto de vista de profissionais que atuam em Varas de Família. Pensando Famílias. v. 20, n. 1, p. 2942, $2016 . \quad$ Disponível em: <http://pepsic.bvsalud.org/scielo.php?script=sci_arttext\&pid=S1679494X2016000100 003\&lng=pt\&nrm=iso\&tlng=pt>. Acesso em: 23 out. 2018 
BENÍTEZ, N. M. C.; CÁRDENAS, C. H. R. La gestación: periodo fundamental para el nacimiento y el desarrollo del vínculo paterno. Avances en Enfermería. v. XXVIII, $n$. 2, $\quad$ p. 88-97, 2010. Disponível em: <https://revistas.unal.edu.co/index.php/avenferm/article/view/21384>. Acesso em: 24 out. 2018

BRASIL. Ministério da Saúde. Secretaria de Atenção à Saúde. Departamento de Ações Programáticas Estratégicas. Coordenação Nacional de Saúde do Homem. Guia do pré-natal do parceiro para profissionais de saúde. Rio de Janeiro; Ministério da Saúde; 2016. 55 p. Disponível em: <http://portalarquivos.saude.gov.br/images/pdf/2016/agosto/11/guia_PreNatal.pdf>. Acesso em: 02 mar. 2018.

BRASIL. Lei no 11.108 de 07 de abril de 2005. Altera a Lei no 8.080, de 19 de setembro de 1990, para garantir às parturientes o direito à presença de acompanhante durante o trabalho de parto, parto e pós-parto imediato, no âmbito do Sistema Único de Saúde - SUS. Presidência da República. Brasília (DF): 2005. Disponível em: <http://www.mulherdemocrata.org.br/legislacao/L11108.pdf>. Acesso: 23 out. 2018

BENAZZI, A. S. T; LIMA, A. B. S; SOUSA, A. P. Pré-natal masculino: um novo olhar sobre a presença do homem. Revista de Políticas Públicas, São Luís, v. 15, n. 2, p. 327-333, jul./dez. 2011. Disponível em: <http://www.periodicoseletronicos.ufma.br/index.php/rppublica/article/view/849/871>. Acesso em: 02 mar. 2018.

CABRAL, Y. P.; PEREIRA, L. P. S.; SOUZA, N. S.; MOTA, S. M. A.; SANTOS, M. S. Pré-natal masculino: estratégia de promoção à saúde do homem. In: I Congresso de saúde DeVry UNIFAVIP - "Saúde Humanizada: sujeitos, práticas e perspectivas em busca de uma qualidade de vida em sociedade", p. 585-586. 2015. Disponível em: <https://even3.azureedge.net/anais/41071.pdf>. Acesso em: 06 mar. 2018

CABRITA, B. A. C.; SILVEIRA, E. S.; SOUZA, A. C.; ALVES, V. H. A ausência do companheiro nas consultas de pré-natal: desafios e conquistas. Revista de Pesquisa: Cuidado é Fundamental Online. v. 4, n. 3, p. 2645-2654, 2012. Disponível em: <https://www.redalyc.org/html/5057/505750894026/>. Acesso em: 18 out. 2018.

CALDEIRA, L. A.; AYRES, L. F. A.; OlIVEIRA, L. V. A.; HENRIQUE, B. D. A visão das gestantes acerca da participação do homem no processo gestacional. Revista de Enfermagem do Centro-Oeste Mineiro. v. 7:e1417, p. 1-10, 2017. Disponível em: <http://www.seer.ufsj.edu.br/index.php/recom/article/view/1417>. Acesso em: 18 out. 2018.

doi: https://doi.org/10.19175/recom.v7i0.1417

CAMPOS, C. P. S.; SAMPAIO A. A importância do pai nas consultas de prénatal. 2015. Disponível em: <http://nippromove.hospedagemdesites.ws/ anais_simposio/arquivos_up/documentos/artigos/12e139eec30944479daa02a0735e 121f.pdf>. Acesso em: $0 \overline{7}$ mar. 2018. 
CARDOSO, V. E. P. S.; SILVA JUNIOR, A. J.; BONATTI, A. F.; SANTOS, G. W. S.; RIBEIRO, T. A. N. A Participação do Parceiro na Rotina Pré-Natal Sob a Perspectiva da Mulher Gestante. Revista de Pesquisa: Cuidado é Fundamental Online. v. 10, n. 3 , p. 856-862, 2018. Disponível em: <www.seer.unirio.br/index.php/cuidadofundamental/article/ download/6252/pdf_1>. Acesso em: 18 out. 2018 doi: http://dx.doi.org/10.9789/2175-5361.2018.v10i3.856-862

COSTA, S. F.; TAQUETTE, S. R. Atenção à gestante adolescente na rede SUS - o acolhimento do parceiro no pré-natal. Revista de Enfermagem UFPE on line. $v$. 11(Supl. 5), p. 2067-74, 2017. Disponível em: <https://periodicos.ufpe.br/revistas/revistaenfermagem/article/viewFile/23360/18984> Acesso em: 18 out. 2018 doi: http://dx.doi.org/10.5205/reuol.9302-81402-1-RV.1105sup201711

DINIZ, C. S. G.; D'ORSI, E.; DOMINGUES, R. M. S. M.; TORRES, J. Á.; DIAS, M. A. B. et al. Implementação da presença de acompanhantes durante a internação para o parto: dados da pesquisa nacional Nascer no Brasil. Cadernos de Saúde Pública. v. $30, \quad$ n. $1, \quad$ p. 140-153, 2014. Disponível em: <http://www.scielo.br/pdf/csp/v30s1/0102-311X-csp-30-s1-0140.pdf>. Acesso em: 22 out. 2018 doi: http://dx.doi.org/10.1590/0102-311X00127013.

FERREIRA, T. N.; ALMEIDA, D. R.; BRITO, H. M.; CABRAL, J. F.; MARIN, H. A. et al. A importância da participação paterna durante o pré-natal: percepção da gestante e do pai no município de Cáceres - MT. Revista Eletrônica Gestão \& Saúde. v. 05, n. $02 . \quad$ p. 337-45. 2014. Disponível em: $<$ http://periodicos.unb.br/index.php/rgs/article/view/22769>. Acesso em: 06 mar. 2018.

GONZALEZ, A. D.; FERNANDES, E. S.; SILVA, E. F.; RABELO, M.; SOUZA, S. R. R. K. A percepção do acompanhante no processo do nascimento. Cogitare Enfermagem. v. 17, n. 2, p. 310-314, 2012. Disponível em: $<$ http://ojs.c3sl.ufpr.br/ojs2/index.php/cogitare/article/view/27889/18497>. Acesso em: 12 mar. 2018.

UNFPA - FUNDO DE POPULAÇÃO DAS NAÇÕES UNIDAS (UNFPA) E INSTITUTO PAPAl. Homens também cuidam! Diálogos sobre direitos, saúde sexual e reprodutiva, paternidade e relações de cuidado. UNFPA e Instituto PAPAI. Recife: UNFPA; Instituto PAPAI, 2007.16p. Disponível em: $<$ http://www.unfpa.org.br/Arquivos/homenstambemcuidam.pdf>. Acesso em: 07 mar. 2018.

HENZ, G. S.; MEDEIROS, C. R. G.; SALVADORI, M. A inclusão paterna durante o pré-natal. Revista de Enfermagem e Atenção à Saúde. v. 6, n. 1, p. 52-66, 2017. Disponível em: <http://seer.uftm.edu.br/revistaeletronica/index.php/enfer/article/view/2053>. Acesso em: 18 out. 2018 
HODNETT, E. D.; GATES, S.; HOFMEYR, G. J.; SAKALA, C. Continuous support for women during childbirth (review). Cochrane Database of Systematic Reviews. v. 7, 2013. Art. No.: CD003766. Disponível em: $<$ http://www.nationalpartnership.org/research-library/maternal-health/cochranereview-continuoussupport-for-women-during-childbirth.pdf>. Acesso em: 07 jul. 2018. doi: 10.1002/14651858.CD003766.pub5.

HOLANDA, S. M.; CASTRO, R. C. M. B.; AQUINO, P. S.; PINHEIRO, A. K. B.; LOPES, L. G. et al. Influência da participação do companheiro no pré-natal: satisfação de primíparas quanto ao apoio no parto. Texto \& Contexto Enfermagem. v. 27, n: 2:e3800016, p. 1-10, 2018. Disponível em: $<$ http://www.scielo.br/scielo.php?pid=S010407072018000200317\&script=sci_abstrac t\&tlng=pt>. Acesso em: 18 out. 2018 doi: http://dx.doi.org/10.1590/0104-070720180003800016

MARQUES S. S. Ampliar a licença-paternidade para despatriarcalizar o estado e a sociedade. Gênero e Direito. v. 4, n. 1, p. 241-260, 2015. Disponível em: <http://www.periodicos.ufpb.br/ojs/index.php/ged/article/view/24479/13615>. Acesso em: 22 out. 2018.

doi: http://dx.doi.org/10.18351/2179-7137/ged.2015n1p241-260

MENDES, K. D. S.; SILVEIRA, R. C. C. P.; GALVÃO, C. M. Revisão integrativa: método de pesquisa para a incorporação de evidências na saúde e na enfermagem. Texto \& Contexto Enfermagem, Florianópolis, v. 17, n.4, p. 758-64, out-dez. 2008. Disponível em: <http://www.scielo.br/scielo.php?script=sci_arttext\&pid= S010407072008000400018>. Acesso em: 03 jan. 2019.

doi: http://dx.doi.org/10.1590/S0104-07072008000400018

KROB, A. D.; PICCININI, C. A.; SILVA, M. R. A transição para a paternidade: da gestação ao segundo mês de vida do bebê. Psicologia USP. v. 20, n. 2, p. 269-291, 2009. Disponível em: <http://www.scielo.br/scielo.php?script=sci_arttext\&pid=S010365642009000200008 >. Acesso em: 18 out. 2018.

OLIVA, T. A.; NASCIMENTO, E. R.; ESPIRÍTO SANTO, F. R. E. Percepções e experiências de homens relativas ao pré-natal e parto de suas parceiras. Revista Enfermagem UERJ. v. 18, n. 3, p. 435-440, 2010. Disponível em: <http://www.facenf.uerj.br/v18n3/v18n3a17.pdf>. Acesso em: 18 out. 2018.

OLIVEIRA, S. C.; FERREIRA, J. G.; SILVA, P. M. P.; FERREIRA, J. M.; SEBRAE, R. A. et al. A participação do homem/pai no acompanhamento da assistência pré-natal. Cogitare Enfermagem. v. 14, n. 1, p. 73-8, 2009. Disponível em: https://revistas.ufpr.br/cogitare/article/view/14118/9489. Acesso em: 18 out. 2018.

PESAMOSCA, L. G.; FONSECA, A. D.; GOMES, V. L. O. Percepção de gestantes acerca da importância do envolvimento paterno nas consultas pré-natal: um olhar de gênero. Revista Mineira de Enfermagem (REME). v. 12, n. 1, p. 182-188, jan./mar., 2008. Disponível em: http://www.reme.org.br/artigo/detalhes/255. Acesso em: 18 out. 2018 
RIBEIRO, J. P.; FERREIRA, J. G.; SILVA, P. M. P.; FERREIRA, J. M.; SEABRA, R. $A$. et al. Participação do pai na gestação, parto e puerpério: refletindo as interfaces da assistência de enfermagem. Revista Espaço para a Saúde. v. 16, n. 3, p. 73-82, jul/set. 2015.

Disponível em: <http://www.uel.br/revistas/uel/index.php/espacoparasaude/article/view/20272/0>. Acesso em: 07 mar. 2018

SANTOS, C. M. C.; PIMENTA, C. A. M.; NOBRE, M. R. C. A estratégia pico para a construção da pergunta de pesquisa e busca de evidências. Revista Latinoamericana de Enfermagem, v. 15. n. 3. mai-jun. 2007. Disponível em: <http://www.scielo.br/pdf/rlae/v15n3/pt_v15n3a23.pdf>. Acesso em: 08 mar. 2018. doi: http://dx.doi.org/10.1590/S0104-11692007000300023

SOUZA, M. T.; SILVA, M. D.; CARVALHO, R. Revisão integrativa: o que é e como fazer. Einstein. v. 8, n. 1, p. 102-106, 2010. Disponível em: <http://www.scielo.br/pdf/eins/v8n1/pt_1679-4508-eins-8-1-0102.pdf >. Acesso em: 10 mar. 2018

SOUZA, S. R. R. K; GUALDA, D. M. R. The experience of women and their coaches with childbirth in a public maternity hospital. Texto \& Contexto Enfermagem. v. 25, n. 1:e4080014, p. 1-10, 2016. Disponível em: <http://www.scielo.br/scielo.php?pid=S010407072016000100309\&script=sci_arttext\& tlng=en>. Acesso em: 24 out. 2018

http://dx.doi.org/10.1590/0104-0707201600004080014

TAKAHASHI, J.; SAHEKI, Y.; GARDIM, S. O que é PICO e PICo?. Universidade de São Paulo. 2014. Disponível em: <https://www.slideshare.net/bibliotecaee/o-quepico-e-pico>. Acesso em: 08 mar. 2018.

YARGAWA, J.; LEONARDI-BEE, J. Male involvement and maternal health outcomes: systematic review and meta-analysis. Journal of Epidemiology and Community Health. v. 69, n. 6, p. 604-612, 2015. Disponível em: <https://jech.bmj.com/content/69/6/604>. Acesso em: 22 out. 2018. doi: https://doi.org/10.1136/jech-2014-

ZAMPIERI, M. F. M. O significado de ser pai na ótica de casais grávidos: limitações e facilidades. Revista Eletrônica de Enfermagem. v. 14, n.3, p. 483-93, 2012. Disponível em: <http://www.fen.ufg.br/revista/v14/n3/v14n3a04.htm>. Acesso em: 18 out. 2018. 